\title{
Research on the Influencing Factors of Traditional Entrepreneurial Curriculum on College Students' Entrepreneurial Tendency
}

\author{
Zhixiang Yuan \\ College of Environmental Sciences, Sichuan Agricultural University, Sichuan, Chengdu, 611130
}

Keywords: science and engineering colleges and universities; entrepreneurial tendency; influencing factors

\begin{abstract}
It is of great theoretical and practical significance to deeply study the key influencing factors of undergraduate entrepreneurial inclination in science and engineering colleges and universities, and to explore the enthusiasm and entrepreneurial ability of undergraduates for their own businesses. Through questionnaires and empirical research, it is proved that entrepreneurial quality, entrepreneurial knowledge, entrepreneurial experience, and entrepreneurial environment are closely related to the entrepreneurial tendencies of college students and are the main influencing factors of college students' entrepreneurial tendencies. The degree of importance of entrepreneurial knowledge and entrepreneurial environment is better than the entrepreneurial quality and entrepreneurial experience. From the perspective of improving the entrepreneurial orientation and entrepreneurial ability of students in science and engineering colleges and universities, it is necessary to strengthen the entrepreneurship education for college students, establish a school-enterprise-integrated student training model, and establish a good entrepreneurial ecological environment.
\end{abstract}

\section{Introduction}

At present, the scale of higher education in our country is continuously expanding. From the perspective of student employment, the development of higher education and social needs are in an inconsistent situation. In view of this mismatch between the scale of higher education and social needs, it is of great practical significance to actively encourage college graduates to solve their own employment problems, realize the value of learning, and effectively contribute to society through self-employment.

There is a misunderstanding in the traditional entrepreneurship curriculum. It is believed that participating in campus activities will affect academic performance. This view does not match the data collected. The learning tasks set by colleges and universities for students are not as large as those in high schools. The completion of learning tasks does not require the entire student's time. This is also related to student learning efficiency. Actively participating in campus cultural activities and serving as a student cadre will help improve the relationship among classmates, increase their experience, and improve their ability to learn independently. This article considers the factors affecting the employment of normal school students based on the cultivation of normal university students. Of course, there are many factors affecting the employment of teacher-training students, such as market demand, policy factors, student employment trends, and family background. The use of data mining tools to find potential links to these factors is also a direction for future research.

\section{Important Theoretical and Practical Significance of Enthusiasm and Entrepreneurial Ability}

Analysis of factors influencing entrepreneurial inclination of students in science and engineering universities

Science and engineering colleges and universities are an important part of China's higher education and an important front for the training of basic research and applied talents. Taking Tsinghua University as a representative, science and engineering universities have played an 
important guiding role in the higher education system. From the perspective of entrepreneurship, due to the cutting-edge nature and practicality of subject knowledge, they have relatively obvious advantages compared to arts and humanities universities when they can effectively understand social needs and adopt appropriate business models.

\subsection{Research object}

Taking the science and engineering college students as the research object, a total of 425 students from 25 universities and colleges were selected for the survey. The selection of the research subjects took the following three main aspects into account:

(1) From the school level, the 985 universities, provincial colleges, and local ordinary colleges are taken into account in three levels, of which the proportions of the three levels of colleges and universities are $20 \%, 40 \%$, and $40 \%$;

(2) From the distribution of the school district, the selection of respondents took into consideration three regions with different economic development rates in the eastern, central and western regions. The proportion of colleges in the three regions was $40 \%, 40 \%$, and $20 \%$, respectively;

(3) From the student level, the selection of survey respondents takes into account the three levels of specialty, undergraduate and graduate students, at 58\%, 32\% and 10\% respectively.

\subsection{Research variables}

Investigations and analysis of college students' entrepreneurial tendencies were conducted from three aspects: entrepreneurial quality, entrepreneurial experience, and entrepreneurial environment.

1) Entrepreneurial quality. The quality of entrepreneurship is mainly manifested in the risk appetite, entrepreneurial enthusiasm and innovation consciousness of the entrepreneurial entity. Theoretical analysis and empirical research at home and abroad have confirmed that entrepreneurial quality is an important aspect of entrepreneurial inclination.

2) Entrepreneurial experience. A certain entrepreneurial experience can provide valuable experience for the entrepreneurial activities of college students. For example, college students can accumulate rich entrepreneurial experiences through the necessary links of entrepreneurial activities such as product creative design, business plan writing, and business reply to participate in the entrepreneurial contest organized by the school, and increase the success rate of entrepreneurship.

3) Entrepreneurial environment. The entrepreneurial environment includes the internal environment of colleges and universities and social environment. The internal entrepreneurial environment of colleges and universities is mainly represented by the campus entrepreneurial culture that is actively fostered by colleges and universities to encourage entrepreneurial activities, encourage bold innovations, and tolerate entrepreneurial failures.

\subsection{Questionnaire design}

The Likert scale is the most commonly used scale, which was established in 1932 by American social psychologist Likert. According to the design of the Likert Scale, five questions were answered: "very willing", "willing", "general", "unwilling", and "extremely unwilling" for college students' "whether they would like to start a business". The importance of entrepreneurial quality, entrepreneurial knowledge, entrepreneurial experience, and entrepreneurial environmental variables is set in five answers: "very important," "important," "general," "not important," and "not important."

In summary, entrepreneurial quality, entrepreneurial knowledge, entrepreneurial experience, and entrepreneurial environment are closely related to the entrepreneurial tendencies of college students and are the main influencing factors of college students' entrepreneurial inclination. The importance of entrepreneurial knowledge and entrepreneurial environment is greater than the entrepreneurial quality and entrepreneurial experience. 


\section{Thoughts and Suggestions for Improving Students' Entrepreneurial Orientation and Entrepreneurial Ability}

From the perspective of improving the entrepreneurial orientation and entrepreneurial ability of students in science and engineering universities, it is necessary to strengthen the entrepreneurship education for college students, establish a school-enterprise-integrated student training model, and build a good entrepreneurial ecological environment.

\subsection{Strengthen students' entrepreneurship education in higher institutions}

In the process of carrying out entrepreneurship education for college students, colleges and universities must focus on the cultivation of their own entrepreneurial qualities such as student decision-making ability, social communication, and innovative spirit. In addition, they should also pay attention to the writing of business plans, business management knowledge, financing and investment, and the need for professional education in the process of entrepreneurship implementation. Through the education of institutions of higher learning, the effective integration of theoretical knowledge and social practice is fully realized, the entrepreneurial awareness and entrepreneurial ability of college students are enhanced, and the success rate of entrepreneurship for college students is improved.

\subsection{Innovate entrepreneurship-oriented student training model}

The traditional higher education model emphasizes the teaching of students' theoretical knowledge, and the cultivation of students' hands-on practical abilities has not received sufficient attention. Therefore, we should actively innovate the entrepreneurial-oriented student training model. Through the combination of school-enterprise education, one can further enrich the curriculum system and education model of higher education, so as to improve the directionality and effectiveness of education. On the other hand, the combination of theory and practice can prompt students to discover their strengths and weaknesses, enhance the internal motivation of independent learning, and inspire students to inspire themselves.

\subsection{Build a sound entrepreneurial ecological environment}

The entrepreneurial activities of college students are inseparable from the good entrepreneurial and ecological environment within the university and society. The cultivation of students' entrepreneurial awareness and the improvement of entrepreneurial ability are not only influenced by the factors of university education, but also influenced by social factors to a large extent. The pros and cons of the entrepreneurial eco-environment determine the level of student's entrepreneurial inclination and the success rate of the students' entrepreneurial success to a great extent.

The student's entrepreneurial tendency is the result of the combined effects of individual factors such as parental occupation, family background, parental qualifications, and educational level, as well as social factors such as group norms, social capital, mass media, and employment equity. Universities and colleges actively build entrepreneurial-oriented student training models by strengthening entrepreneurship education for undergraduates and establishing entrepreneurial-oriented student training models. The improvement of college students' entrepreneurial awareness and entrepreneurial ability also depend on the establishment of a positive attitude of college students, the improvement of the sense of innovation, the improvement of self-study ability, the improvement of individual qualities required for starting a business, and the creation of a fair entrepreneurial environment.

\section{References}

[1] Gao Xuechun, Chen Weihua. The Game of Ideals and Reality: The Dilemma and Countermeasures for the Free Employment of Normal Students [J]. China Adult Education, 2014, (5). 
[2] Tian Li. A model of influencing factors of undergraduates' entrepreneurial tendency-Taking Guangdong university students as an example [J]. Journal of Yunnan Institute of Socialism, 2013, (5):131-133.

[3] Gao Jing, He Changzheng, Liu Jiao. Research on the Influencing Factors of Undergraduates' Start-up Tendency Based on SEM Model: Empirical Data from Chongqing [J]. Educational Development Research, 2014, (1):57-62.

[4] Hu Yongqing. Research on the influencing factors of college students' entrepreneurial tendency based on the theory of planned behavior [J]. Educational Development Research, 2014, (9): 77-82.

[5] Jiang Yan. Structural equations and empirical research on the influencing factors of undergraduates' entrepreneurial tendencies: A case study of university students in Wenzhou [D]. Zhejiang Gongshang University, 2008, (1). 